\title{
Research Paper: The Effectiveness of Assertiveness Training on Bullying, Competitive State Anxiety and Performance Under Pressure in Futsal Players
}

\author{
Reza Aliyar Najafabadi ${ }^{1}$ (D), Zohreh Meshkati ${ }^{1 *}$ (D), Rokhsareh Badami ${ }^{1}$ (D)
}

1. Department of Physical Education and Sport Science, Isfahan (Khorasgan) Branch, Islamic Azad University, Isfahan, Iran

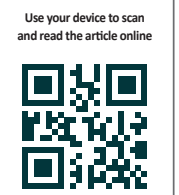

ditation Aliyar Najafabadi R, Meshkati Z, Badami R. The Effectiveness of Assertiveness Training on Bullying, Competitive State Anxiety and Performance Under Pressure in Futsal Players. Journal of Research \& Health. 2020; 10(5):339-348. http:// dx.doi.org/10.32598/JRH.10.5.21.7.98

dof : http://dx.doi.org/10.32598/JRH.10.5.21.7.98

\section{(i) (3)}

Article info:

Received: 13 Dec 2019

Accepted: 20 May 2020

Publish: 01 Sep 2020

\section{Keywords:}

Assertiveness, Bullying, Anxiety, Athletic performance

\section{A B STRACT}

Background: Assertiveness is a life skill designed to improve attitudes and assertive behavior. Assertiveness changes one's point of view toward oneself to achieve self-confidence, better interpersonal communication, and individual well-being. This study aims to determine the effectiveness of assertiveness training on bullying, competitive state anxiety, and performance under pressure in futsal players.

Methods: The study population consisted of all adolescent male futsal players of 15-17 years old in Isfahan City, Iran in 2017. This research was a controlled quasi-experimental field study with a Pre-test-Post-test design. Out of the study population, 32 futsal players with low to moderate scores in assertiveness questionnaire were selected by targeted sampling method and then they were randomly divided into two groups of experimental and control. The experimental group received 8 assertiveness training sessions. The study data were collected by Gambrill-Richey assertiveness inventory, University of Illinois bully scale, competitive state anxiety inventory-2, and athletic performance questionnaire.

Results: The results of univariate ANCOVA in bullying, competitive state anxiety, and performance under pressure showed a significant difference between the two groups after the intervention $(\mathrm{P}<0.05)$. All in all, the results showed the effectiveness of assertiveness training on reducing bullying and competitive state anxiety and improving the performance under pressure in adolescent male futsal players.

Conclusion: It is recommended that assertiveness training be used to improve performance under pressure in futsal players.

\footnotetext{
* Corresponding Author:

Zohreh Meshkati, PhD.

Address: Department of Physical Education and Sport Science, Isfahan (Khorasgan) Branch, Islamic Azad University, Isfahan, Iran.

Phone: +98 (31) 32227719

E-mail:zmeshkati@gmail.com
} 


\section{Introduction}

oday, technological advances have changed profoundly various aspects of human life, especially in the psychological and social aspects. This transformation requires more knowledge and skills to establish interpersonal and social communications. Meanwhile, learning skills that can improve interpersonal communications and promote social skills will be an effective way to improve mental health. Social skills usually improve people's attitudes toward their abilities [1]. To achieve this goal, assertiveness as a life skill is designed to improve attitudes and assertive behavior. It contributes to change one's attitude toward oneself and to achieve self-confidence, interpersonal communication, and individual well-being [2].

There are three responding styles of assertive, aggressive, and passive in interpersonal communications. Aggressive behavior is conscious behavior that results in physical or psychological suffering. Passive behavior indicates a person's lack of respect for his or her needs and rights. A submissive person is more vulnerable than being able to confront and accept participation responsibilities [3]. Assertiveness has also been considered as one of the amendable aspects of interpersonal communications [2].

A problematic interpersonal situation is the bullying phenomenon. Bullying in the general sense is an act of aggression in which individual(s) attack others, beat them, or are repeatedly aggressive towards weaker people [4]. Those committing bullyings have a positive view of aggression and feel a great need for dominating others [5]. Researchers have also approved the correlation between social skills and bullying [6].

Participation in sports activities is shown to bring benefits such as physical, mental, and personality improvements, teamwork, and cooperation improvement [7], self-esteem, self-efficacy, self-control, respect for others [2], and individual assertiveness. The assertiveness skill itself helps improve self-confidence and interpersonal communications [8]. On the other hand, psychological factors affect sports and exercise performance [9]. Because of the close competition of elite athletes, only those will succeed that besides physical readiness, have high psychological readiness, too [10].

Anxiety and pressure are the main psychological factors affecting exercise and normal life [11]. Spielberger divided anxiety into two categories of state and trait anxiety [12]. Trait anxiety is behavior that results from one's personality, according to which an individual may assess a wide range of typical situations as a threat [13]. State anxiety is a temporary and unstable emotional state that varies depending on the situation and is due to the individual's perception of the current situation as a threat and is often associated with autonomic nervous system activity [11].

In addition to experiencing negative thoughts and understanding physiological activity, one's belief in one's ability to confront challenges is also important in creating anxiety [14]. It has been observed that athletes will have low performance in specific competitions if they have not acquired the ability to cope with anxiety [15]. Competitive state anxiety affects the performance of athletes. A higher competitive state anxiety level lowers the athlete's performance level during the competition. As a result, the athlete loses his efficiency, which reflects the perceived mismatch between environmental demands and the athlete's ability to fulfill those demands to achieve appropriate results [16].

Beilock and Carr have also defined psychological pressure as a willingness to worry in situations with high levels of skills [17]. Anxiety increases under the pressure. Thus, in conditions with high psychological pressure, the athlete's performance decreases compared to the athlete's performance before the condition and is expected to repeat it [18].

Few studies have investigated the effect of assertiveness on bullying and competitive state anxiety in the literature. Some studies have addressed behavioral interventions. Their results indicated that assertiveness training reduced anxiety, stress, depression [19], physical and verbal aggression, anger, and hostility in students [20]. Pearsall and Ellis showed that assertiveness affects team performance and satisfaction [21]. Sharma also examined the relationship between competitive state anxiety and performance of 119 soccer players. The results showed a negative correlation between competitive state anxiety and performance of soccer players [16].

In general, a review of the literature shows that most studies have been conducted on non-athlete samples and no research has been done to investigate the effects of assertiveness on performance under pressure, yet. Therefore, it is necessary to study these variables in athletes and especially in futsal because of high levels of contacts and pressures during competition. This study aimed to examine the effectiveness of assertiveness training on bullying, competitive state anxiety, and performance under pressure in futsal players. 
Table 1. Assertiveness training session's summary

\begin{tabular}{|c|c|}
\hline Session & Summary of Assertiveness Training \\
\hline 1 & $\begin{array}{l}\text { Defining sports psychology and showing video clips, expressing the necessity of assertiveness and its benefits in everyday } \\
\text { life and sports, including futsal. Giving assignments to remember situations in which the individual has acted non-assert- } \\
\text { ively, especially during futsal and his reaction to those situations. }\end{array}$ \\
\hline 2 & $\begin{array}{l}\text { Reviewing previous session assignments and getting feedback. Discussing the rights of individuals and familiarizing } \\
\text { athletes with their rights, including the right to express or not to express opinions, the right to freedom of choice, and the } \\
\text { right to have a fair competition. Giving assignments about dealing with new situations and reacting to them. }\end{array}$ \\
\hline 3 & $\begin{array}{l}\text { Reviewing previous session assignments and getting feedback. Discussing assertion-based behaviors and alternative } \\
\text { behaviors, including discussing different types of behavior and specific ways to cope with change. Giving assignments on } \\
\text { detecting assertive behavior as well as other behaviors (aggressive and passive) and the burden of a relationship. }\end{array}$ \\
\hline 4 & $\begin{array}{l}\text { Reviewing previous session assignments and getting feedback. Discussing anger and its consequences. Describing some } \\
\text { of implicit anger symptoms and methods of expressing or not expressing anger in the futsal environment, and showing } \\
\text { video clips. Giving assignments for staying calm and controlling anger in different situations of playing futsal. }\end{array}$ \\
\hline 5 & $\begin{array}{l}\text { Reviewing previous session assignments and getting feedback. Discussing the pros and cons of anger, including psycho- } \\
\text { logical stress relief, the release of feelings, and achievement of goals; methods of coping with anger; and guidelines for } \\
\text { expressing anger. Assignments on coping with anger. }\end{array}$ \\
\hline 6 & $\begin{array}{l}\text { Reviewing previous session assignments and getting feedback. Discussing requesting, saying "Yes" or "No" to others' } \\
\text { requests, determining reasons for not being able to say "No," and giving assignments. }\end{array}$ \\
\hline 7 & $\begin{array}{l}\text { Reviewing previous session assignments and getting feedback. Discussing criticism. Appropriate and effective responses } \\
\text { to criticism and coping with it. Pros and cons of criticism and playing video clips. Giving assignment. }\end{array}$ \\
\hline 8 & $\begin{array}{l}\text { Reviewing previous session assignments and getting feedback. Providing special techniques for difficult situations and } \\
\text { ways to increase assertion. Reviewing and concluding previous sessions. }\end{array}$ \\
\hline
\end{tabular}

\section{Methods}

This was a quasi-experimental and field study with a Pre-test-Post-test design and a control group using targeted sampling and random allocation of samples to the groups. In the present study, the independent variable was assertiveness and the dependent variables were bullying, competitive state anxiety, and performance under pressure. The study population consisted of 94 adolescent futsal players in Isfahan City, Iran aged 1517 years. The inclusion criteria were having at least one year of experience in playing futsal, being 15-17 years old, and lack of familiarity with the interventions and training used in this research.

First, the assertiveness questionnaire or GambrillRichey Assertion Inventory (GRAI) was completed by all players. After scoring, the way of performing necessary interventions, the number of sessions, how to complete questionnaires, and other executive programs were explained to 43 players with low to moderate scores [2226], of whom 32 were willing to participate in the study and signed informed consent forms. Then, the subjects were randomly divided into two groups of experimental and control ( $\mathrm{n}=16$ for each).

At first, all the participants were Pre-tested for bullying and competitive state anxiety. Also, the coaches completed the athletic performance checklist after a formal match with the presence of spectators as psychological pressure. The experimental group underwent assertiveness training (Table 1), but the control group did not. After applying the protocol, all participants were subjected to the Post-test with Pre-test conditions. The training protocol consisted of eight 90-minute sessions of assertiveness training (Boket et al., 2016).

\section{Research Tools}

\section{Gambrill-Richey assertion inventory (GRAI)}

The standard Gambrill-Richey assertion inventory (GRAI; 1975) was developed to measure individuals' assertiveness. GRAI has 22 items scored based on a 5-point Likert scale (from "I do not get sad at all"=1, to "I get very sad" $=5$ ). Scores of 32-44 indicate low assertiveness, 44-66 indicate moderate, and above 66 indicates high assertiveness. The reliability of GRAI was found 0.81 by calculating the Cronbach alpha. GRAI was translated and standardized by Besharat in Iran and had a high correlation validity $(0.76)$ with the original GRAI. The Cronbach alpha coefficient of 0.81 approved its reliability [22].

\section{University of Illinois bully scale (UIBS)}

University of Illinois Bully Scale (UIBS) (Espelage and Holt, 2001) has 18 items and three subscales of bully, victim, and fighting. Items are scored based on a 5-point Likert scale from 1 (Never) to 5 (Seven times or more) and each subscale has a separate score. Validity and reli- 
ability of UBIS in Iran were investigated by Chalme and reported the Cronbach alpha coefficients with split-half and test-retest methods for the whole scale and its subscales from 0.62 to 0.90 , and concluding that UBIS has proper validity and reliability in Iranian society [23].

\section{Competitive state anxiety Inventory-2 (CSAI-2R)}

Competitive state anxiety Inventory-2 (CSAI-2R) (Cox et al., 2003) was developed for assessing competitive state anxiety has 17 items and three subscales of cognitive anxiety, somatic anxiety, and self-confidence. The subscales of cognitive anxiety and self-confidence each have 5 items and the somatic anxiety subscale has 7 items. Items are answered based on a 4-point Likert scale of 1 (not at all) to 4 (a lot). Mehr Safar, Moghadam Zade, Gharayagh Zandi, and Sanaifar reported satisfactory reliability and validity for CSAI-2R and the Cronbach alpha coefficient of above 0.70 for the total scale and all its subscales [24].

\section{Athletic performance questionnaire}

This questionnaire was designed by Charbonneau in 2001 to assess the performance of athletes. It has five items scored based on a 5-point Likert scale from 1 (poor) to 5 (excellent). The scores of each athlete are given by the coach after a competition. Its mean reliability coefficient was reported as 0.71 by Charbonneau. Sha'bani Bahar, Yaghoobi, and Farooqi (2010) reported appropriate validity and reliability for it. Its test-retest reliability had a Cronbach alpha of 0.73 [25].

Univariate ANCOVA with Pre-test control was used to analyze the data. Statistical analyses were performed using SPSS V. 23 at a significance level of $\mathrm{P}<0.05$.

\section{Results}

Table 2 presents the Pre-test and Post-test descriptive results of the study variables. The results of the Kolmogorov-Smirnov test were not significant for the scores of bullying $(\mathrm{P}=0.149)$, competitive state anxiety $(\mathrm{P}=0.2)$, and performance under pressure $(\mathrm{P}=0.284)$ variables, indicating the normal distribution of data. Also, Levene's test results were not significant for bullying $(\mathrm{P}=0.745)$, competitive state anxiety $(\mathrm{P}=0.64)$, and performance under pressure $(\mathrm{P}=0.334)$ variables, indicating homogeneity of variances. ANCOVA was hence used for data analysis.

Main hypothesis: Eight sessions of assertiveness training will decrease bullying and competitive state anxiety

Table 2. The Mean \pm SD of Pre-test and Post-test scores of the research variables by groups

\begin{tabular}{cccc}
\hline Variable & Group & \multicolumn{2}{c|}{ Mean \pm SD } \\
\cline { 3 - 4 } & & Pre-test & Post-test \\
\hline Bullying & Experimental & $32.93 \pm 6.38$ & $27.5 \pm 4.24$ \\
& Control & $31.31 \pm 8.22$ & $32.12 \pm 9.79$ \\
Anxiety is a competitive state & Experimental & $41.43 \pm 4.86$ & $35.93 \pm 4.44$ \\
& Control & $39.62 \pm 7.69$ & $39.68 \pm 6.53$ \\
Under pressure operation & Experimental & $17.18 \pm 1.89$ & $18.87 \pm 1.74$ \\
& Control & $18.37 \pm 1.25$ & $18.68 \pm 1.62$ \\
\hline
\end{tabular}

Table 3. Groups ANCOVA results in reducing bullying

\begin{tabular}{cccccccc}
\hline Source of Changes & Sum of Squares & df & Mean Squares & F & P & Effect Size & Statistical Power \\
\hline Pre-test & 833.924 & 1 & 833.924 & 27.613 & 0.001 & 0.488 & 0.999 \\
Group membership & 264.688 & 1 & 264.688 & 8.764 & 0.006 & 0.232 & 0.816 \\
Error & 875.826 & 30 & 30.201 & & & & \\
\hline
\end{tabular}


Table 4. Groups ANCOVA results in decreasing competitive state anxiety

\begin{tabular}{cccccccc}
\hline Source of Changes & Sum of Squares & df & Mean Squares & F & P & Effect Size & Statistical Power \\
\hline Pre-test & 186.545 & 1 & 186.545 & 7.196 & 0.012 & 0.199 & 0.737 \\
Group membership & 150.352 & 1 & 150.352 & 5.799 & 0.023 & 0.167 & 0.744 \\
\hline Error & 751.83 & 30 & 25.925 & & & \\
\hline
\end{tabular}

MPA

Table 5. Groups ANCOVA results in increasing performance under pressure

\begin{tabular}{cccccccc}
\hline Source of Changes & Sum of Squares & df & Mean Squares & F & P & Effect Size & Statistical Power \\
\hline Pre-test & 66.632 & 1 & 66.632 & 104.141 & 0.001 & 0.782 & 1.000 \\
Group membership & 11.741 & 1 & 11.741 & 18.35 & 0.001 & 0.388 & 0.985 \\
Error & 18.55 & 30 & 0.64 & & & & \\
\hline
\end{tabular}

MP:

and increase performance under pressure in adolescent male futsal players.

To test the main hypothesis, three sub-hypotheses were tested:

First sub-hypothesis: Eight sessions of assertiveness training will decrease bullying in adolescent male futsal players.

Table 3 presents the ANCOVA results of groups in reducing bullying after interventions and assertiveness training.

ANCOVA results of groups in decreasing bullying after interventions and assertiveness training showed that after adjusting Pre-test scores, there was a significant difference between the groups $(\mathrm{P}=0.006)$, indicating the effectiveness of the intervention. Therefore, the first sub-hypothesis of the research is confirmed. That is, assertiveness training decreases bullying. The effectiveness of training at the Post-test was 0.232 . That is, about $23.2 \%$ of the bullying variance is related to group membership or the effect of training. The statistical power of $81.6 \%$ showed the appropriate statistical accuracy of the test. Additionally, the sample size was sufficient to test this hypothesis.

Second sub-hypothesis: Eight sessions of assertiveness training decreases competitive state anxiety in adolescent male futsal players.
Table 4 presents the ANCOVA results of groups in decreasing competitive state anxiety after interventions and assertiveness training.

ANCOVA results of groups in reducing competitive state anxiety after interventions and assertiveness training showed that after adjusting Pre-test scores, there was a significant difference between the groups $(\mathrm{P}=0.023)$, indicating the effectiveness of the intervention. Therefore, the second sub-hypothesis of the research is confirmed. That is, assertiveness training decreases competitive state anxiety. The effectiveness of training at the Post-test was 0.167 . That is, about $16.7 \%$ of the competitive state anxiety variance is related to group membership or the effect of training. The statistical power of $74.4 \%$ showed the appropriate statistical accuracy of the test. Additionally, the sample size was sufficient to test this hypothesis.

Third sub-hypothesis: Eight sessions of assertiveness training increases performance under pressure in adolescent male futsal players.

ANCOVA results of groups in increasing performance under pressure after interventions and assertiveness training showed that after adjusting Pre-test scores, there was a significant difference between the groups $(\mathrm{P}=0.001)$, indicating the effectiveness of the intervention (Table 5). Therefore, the third sub-hypothesis of the research is confirmed. That is, assertiveness training increases performance under pressure. The effectiveness of training at the Post-test was 0.388 . That is, about $38.8 \%$ of the performance under pressure variance is related to group 
membership or the effect of training. The statistical power of $98.5 \%$ showed the appropriate statistical accuracy of the test. Additionally, the sample size was sufficient to test this hypothesis.

\section{Discussion}

This study aimed to determine the effectiveness of assertiveness training on bullying, competitive state anxiety, and performance under the pressure of futsal players and showed evidence of assertiveness training effects on these variables. The results showed that assertiveness training of adolescent male futsal players increased their assertiveness level. This is consistent with the findings of Alkaya and Avsar and Gundogdu [8, 26]. It appears that after assertiveness training, the individual becomes more assertive in communication and correctly expressing himself to others upon becoming acquainted with his rights and the correct form of controlling and expressing his feelings to others, which increases assertiveness facing others.

Another finding was that assertiveness training of adolescent male futsal players decreased bullying in them. This result was consistent with the findings of Dehnavi and Ebrahimi and Aktop et al. [20, 27], but not with Alkaya and Avsar's findings [8]. It appears that a significant decrease in bullying in this study was because the players had limited ways of establishing the right relationship with others before training, which has led to wrong behaviors, and sometimes bullying, in certain circumstances. Individuals need to acquire psychological skills in interacting positively with each other, who, by acquiring these skills, will have more and better ways to communicate and replace bullying. After training, this replacement improved interpersonal communication and thus reduced bullying in athletes [28].

Based on the theory of behaviorism, efficient communication beliefs facilitate people's adaptation in their communication and promote their health and development. In contrast, inefficient communication beliefs are too exaggerated, rigid, irrational, and absolute beliefs about ourselves and relationships with others that reduce individual resistance to problems and cause the greatest frustration and failure [29]. In this regard, assertiveness training increases individuals' ability to adapt proper communication, which can improve an individual's health and reduce a sense of frustration and thus create healthy relationships.

Also, from the psychosocial perspective, rules governing perceptions and limits governing mental interactions are involved in the process of mental communication with the outside world, resulting in a common consequence in the social dimension, i.e., misunderstanding in interpersonal communications [29]. Assertiveness training eliminates many of these misunderstandings and improves the communication process. The inconsistency between this study and Alkaya and Avsar might be because of different educational protocols and the cultural differences of the samples.

In this study, assertiveness training decreased competitive state anxiety in adolescent male futsal players. This finding is consistent with the findings of Lesure-Lester and Larijani et al. [30, 31]. In explaining this finding, it should be said that anxiety is linked to some situations through learning and is also observed in subsequent situations, and the individual never considers re-evaluating the threat or finding a way to cope with it. A person's adequacy provides exposure responses that reduce anxiety. Learning coping skills, a person becomes more assertive in re-evaluating threatening situations.

This courage in facing fear reduces one's anxiety. Wolpe also argues that courageous behaviors are contradictory with anxiety. Therefore, if one exists, the other will disappear. He also suggests that an anxious person cannot express his feelings because he is worried about losing friends or their respect. Anxious people have less courage and fear negative evaluations [32]. The psychological theory believes that anxiety is caused by the fear of communicating with others and being evaluated. Assertiveness training appears to reduce the anxiety of a person due to its nature, which includes how to communicate and express feelings in a manner that is right and respectful of others' rights [33].

The last finding of this study showed that assertiveness training improved performance under pressure in adolescent male futsal players. There was no study evaluating the effects of assertiveness training on performance under pressure that can be compared with this study. Only Pearsall and Ellis investigated the effect of assertiveness skill on team performance without pressure conditions, which showed that assertiveness positively affects team performance and satisfaction [21]. Regarding this finding, it can be stated that psychological pressure coping strategies are performance decrease moderators. Acquiring psychological skills, an individual learns better ways to deal with pressure and its moderation and has better performance in high psychological pressure situations [34]. Among psychosocial skills, assertiveness can be learned. So, it helps individuals in dealing with problems and coping with internal and external pressures. Assertiveness improves people's performance, especially under psychological pressure conditions [35]. 


\section{Conclusion}

In the present study, people learn self-expression methods and this training will increase their level of assertiveness. In explaining the reduced bullying level in players after assertiveness training, it should be noted that part of the training of this skill relates to improve methods of establishing correct communication between individuals and respecting others' rights. By respecting others' rights, the form of communication moves from arrogant to respectful and demands one's own right in a rational way, which in turn reduces interpersonal tensions, particularly bullying.

Concerning the reduction of competitive state anxiety and improvement of performance under pressure, it should be noted that the nature of anxiety is a competitive state of fear of the situation. With assertiveness training, individuals face and confront unrealistic and pressure-inducing fears. Individuals who are coping with anxiety and stress can have a better performance, and this improvement will repeat this process in the future.

Ultimately, assertiveness training and interventions were significantly effective in reducing bullying and competitive state anxiety and improving performance under the pressure of futsal players. It is worth noting that the players' benefitted from assertiveness training acknowledged its effectiveness in being calm and having better self-confidence and ultimately better performance. Since the assertiveness training program is not expensive and practical, it is suggested that players, coaches, and sports team managers be familiarized with assertiveness skills to prepare a better team and better players. The results of this study can help athletes, especially in high-anxiety competitions.

Since this was the first study of this kind in the sports community, there is an urgent need for its repetition in other samples to obtain results for empirical comparisons and confirmations. According to the results of other studies on the effect of age, gender, and skill level on assertiveness [36], it is suggested that studies be conducted on samples with a different age range and in different societies to generalize and compare the results. It is also suggested that future studies be more extensive with long-term follow-ups to determine the effect of assertiveness training after a longer period.

\section{Ethical Considerations}

\section{Compliance with ethical guidelines}

Ethical approval for this article has been registered under the license No. 99-04-14-2-1383.

\section{Funding}

This research did not receive any grant from funding agencies in the public, commercial, or non-profit sectors.

\section{Authors' contributions}

Data collection, data analysis: Reza Aliyar Najafabadi; Manuscript preparation: Zohreh Meshkati; Study design, approval of the final version: All authors.

\section{Conflict of interest}

The author declared no conflict of interest.

\section{Acknowledgments}

The author would like to thank all the futsal players and coaches who helped us collect the information.

\section{References}

[1] Zeraat Z, Ghafourian A. [Effectiveness of problem solving skill teaching on student'educational self thought (Persian)] Educ Strateg Med Sci. 2009; 2(1):23-6. https://www.sid.ir/ en/journal/ViewPaper.aspx?id=188618

[2] Lin YR, Shiah IS, Chang YC, Lai TJ, Wang KY, Chou KR Evaluation of an assertiveness training program on nursing and medical students' assertiveness, self-esteem, and interpersonal communication satisfaction. Nurse Educ Today. 2004; 24(8):656-65. [DOI:10.1016/j.nedt.2004.09.004] [PMID]

[3] Xie X, Chen W, Lei L, Xing C, Zhang Y. The relationship between personality types and prosocial behavior and aggression in Chinese adolescents. Pers Individ Dif. 2016; 95:56-61. [DOI:10.1016/j.paid.2016.02.002]

[4] Wang J, Iannotti RJ, Luk JW. Patterns of adolescent bullying behaviors: Physical, verbal, exclusion, rumor, and cyber. J Sch Psychol. 2012; 50(4):521-34. [DOI:10.1016/j. jsp.2012.03.004] [PMID] [PMCID]

[5] Glew GM, Fan MY, Katon W, Rivara FP. Bullying and school safety. J Pediatr. 2008; 152(1):123-8.e1. [DOI:10.1016/j. jpeds.2007.05.045] [PMID] [PMCID]

[6] Rubin KH, Bukowski WM, Parker JG. Peer interactions, relationships, and groups. In: Eisenberg N, Damon W, Lerner RM, editors. Handbook of child psychology: Vol. 3. Emotion- 
al and personality development, $6^{\text {th }}$ ed. Hoboken: Wiley; 2006 [DOI:10.1002/9780470147658.chpsy0310]

[7] Yilmaz A. The effect of sport on life skills of athlete-students in different education levels: Mixed research approach. Kastamonu Eğitim Dergisi. 2020; 28(3):1233-43. https:// dergipark. org.tr/en/pub/kefdergi/issue/54020/725768

[8] Avşar F, Alkaya SA. The effectiveness of assertiveness training for school-aged children on bullying and assertiveness level. J Pediatr Nursing. 2017; 36:186-90. [DOI:10.1016/j. pedn.2017.06.020]

[9] Zehtab Najafi A, Vaez Mousavi SMK, Taheri HR. [Effectiveness of selected psycological interventions on reducing competitive state anxtty of athletes (Persian)]. Sport Manage Mot Behav J. 2018; 8(15):19-27. http://jrsm.khu.ac.ir/article-1-2701-en.html

[10] Lane AM, Terry PC, Stevens MJ, Barney S, Dinsdale SL. Mood responses to athletic performance in extreme environments. J Sports Sci. 2004; 22(10):886-97. [DOI:10.1080/02640410400005875] [PMID]

[11] Weinberg RS, Gould D. Foundations of Sport and Exercise Psychology, $6^{\text {th }}$ ed. Champaign: Human Kinetics; 2014.

[12] Spielberger CD. State-Trait anxiety inventory. The Corsini encyclopedia of psychology [Internet]. 2010 [Updated 2010 Jan 30]. [DOI:10.1002/9780470479216.corpsy0943]

[13] Berchio C, Rodrigues J, Strasser A, Michel CM, Sandi C. Trait anxiety on effort allocation to monetary incentives: A behavioral and high-density EEG study. Transl Psychiatry. 2019; 9(1):174. [DOI:10.1038/s41398-019-0508-4] [PMID] [PMCID]

[14] Cheng WNK, Hardy L, Markland D. Toward a three-dimensional conceptualization of performance anxiety: Rationale and initial measurement development. Psychol Sport Exerc. 2009; 10(2):271-8. [DOI:10.1016/j.psychsport.2008.08.001]

[15] Pieter W, Wong R, Ampongan C. Mood and experience as correlates of performance in young Filipino taekwondo athletes. Acta Kinesiologiae Tartuensis. 2006; 11: 64-72. https:// dspace.ut.ee/bitstream/handle/10062/54777/acta_kinesiologiae_11_ocr.pdf?sequence $=4 \&$ isAllowed $=\mathrm{y}$

[16] Sharma R, Yadav RK. A comparison of precompetition anxiety of male and female badminton players. Indian J Phys Educ Sport appl Sci. 2012; 5(1):1-39. https:/ / www.semanticscholar.org/paper/X-Sports-Scientists-Views-in-IJPESAS1-A-COMPARISON-Sharma-Yadav/2feeabe0ba969927494bc 8f1245ba5035b265d25?p2df

[17] Beilock SL, Carr TH. On the fragility of skilled performance: What governs choking under pressure? J Exp Psychol Gen. 2001; 130(4):701-25. [DOI:10.1037/0096-3445.130.4.701]

[18] Mesagno C, Mullane-Grant T. A comparison of different pre-performance routines as possible choking interventions. J Appl Sport Psychol. 2010; 22(3):343-60. [DOI:10.1080 /10413200.2010.491780]

[19] Eslami AA, Rabiei L, Afzali SM, Hamidizadeh S, Masoudi R. The effectiveness of assertiveness training on the levels of stress, anxiety, and depression of high school students. Iran Red Crescent Med J. 2016; 18(1):e21096. [DOI:10.5812/ircmj.21096]

[20] Dehnavi F, Ebrahimi MI. Effect of assertiveness skills training on the level of aggression in high school first grade female students in Qorveh city. Int J Humanit Cult Stud (IJHCS)
ISSN 2356-5926. 2016; 2016:1421-34. http://www.ijhcs.com/ index.php/ijhcs/article/download/2295/2091

[21] Pearsall MJ, Ellis AP. The effects of critical team member assertiveness on team performance and satisfaction. J Manage. 2006; 32(4):575-94. [DOI:10.1177/0149206306289099]

[22] Mirzakhani N, Kangarani Farahani M, Rezaee M, Akbarzadeh Baghban A, Sadeghi E. [Comparison of assertiveness skills and anxiety between students with learning disability and typical peers in elementary schools of Tehran (Persian)] Sci J Rehabil Med. 2016; 5(2):209-17. https:/ /www.sid.ir/en/ Journal/ViewPaper.aspx?ID=537811

[23] Safara M, Moazamabadi M. [Effectiveness of positive thinking on reducing bullying and increasing emotional independence adolescents in tabas (Persian)]. Clini Psychol Stud. 2018; 8(29):161-76. https://iluk.ir/en/journal/ViewPaper aspx?ID=606551

[24] Mehr safar A, Moghadam zade A, Gharayagh zandi H, Sanaifar F. [Psychometric Properties of the Revised Persian Version of the Competitive Situation-2 Anxiety Questionnaire in Tehran Athletes (Persian)]. J Educ Meas. 2016; 6(23):189211. http://jem.atu.ac.ir/article_5738.html

[25] Shabani Bahar GR, Samadi A, Momeni Piri S. [The relationship between Intellectual and Emotional cycles with respect to Biorhythm Theory and athletes' sport performance (Persian)]. Sport Psychol Rev. 2013; 2(3):13-28. https://spsyj.ssrc ac.ir/article_131_en.html

[26] Gündoğdu R. Effect of the creative drama-based assertiveness program on the assertiveness skill of psychological counsellor candidates. Educ Sci: Theory Pract. 2012; 12(2):687-93. https://www.researchgate.net/publication/298422019_Effect_of_the_Creative_Drama-Based_Assertiveness_Program_on_the_Assertiveness_Skill_of_Psychological_Counsellor_Candidates

[27] Aktop A, Özçelik M, Kaplan E, Seferoğlu F. An examination of assertiveness and aggression level of amateur soccer players in different age groups. Procedia Soc Behav Sci. 2015; 174: 1928-32. [DOI:10.1016/j.sbspro.2015.01.857]

[28] Gahanger Boket E, Bahrami M, Kolyaie L, Hosseini SA The effect of assertiveness skills training on reduction of verbal victimization of high school students. Inte J Humanit Cult Stud. 2016; 3(2):690-99. https://www.ijhcs.com/index.php/ ijhcs/article/view/2857

[29] Moshtaghi M, Atashpour HR, Aghaei A, Allameh SF. [The efficacy of humanism group training on married women's relationship beliefs who confer to consulting or cultural-educational centers in Isfahan (Persian)]. Quarterly Counseling and Psychotherapy Family 2012; 2(3):322-39. https://www. researchgate.net/publication/281465642_The_efficacy_of_ humanism_group_training_on_married_women's_relationship_beliefs_who_confer_to_consulting_or_cultural-educational_centers_in_Isfahan

[30] Lesure-Lester GE. Dating competence, social assertion and social anxiety among college students. Coll Stud J2001; 35(2):317.

[31] Larijani T, Aghajani M, Baheiraei A, Neiestanak N. Relation of assertiveness and anxiety among Iranian University students. J Psychiatr Ment Health Nurs. 2010; 17(10):893-9. [DOI:10.1111/j.1365-2850.2010.01607.x] [PMID] 
[32] Wolpe J. Inadequate behavior analysis: The achilles heel of outcome research in behavior therapy. J Behav Ther Exp Psychiatry. 1977; 8(1):1-3. [DOI:10.1016/0005-7916(77)90095-7]

[33] Paterson M, Green J, Basson C, Ross F. Probability of assertive behaviour, interpersonal anxiety and self-efficacy of South African registered dietitians. J Hum Nutr Diet. 2002; 15(1):9-17. [DOI:10.1046/j.1365-277X.2002.00326.x] [PMID]

[34] Williams JM, Krane V. Psychological characteristics of peak performance. In: Williams JM, editor. Applied sport psychology: Personal growth to peak performance, $4^{\text {th }}$ ed. Mayfield: Mountain View; 2001.

[35] Fodor EM, Wick DP, Hartsen KM. The power motive and affective response to assertiveness. J Res Pers. 2006; 40(5):598610. [DOI:10.1016/j.jrp.2005.06.001]

[36] Coskuner Z, Coban B, Savucu Y, Gacar A, Genc E. A study on assertiveness level of college students who are doing orienteering sports. Adv in Environ Biol. 2013; 7(4):725-29. [DOI:10.2139/ssrn.2198836] 
This Page Intentionally Left Blank 